\title{
Magnetic Thermoresponsive Nanocomposite for Targeted PARP-1 in Colorectal Adenocarcinoma, an Approach for Tumor Dual Therapy
}

\section{Alaa Gamal}

Ain Shams University Faculty of Science

\section{El-Sayed El-sayed}

Ain Shams University Faculty of Science

Tarek El-Hamoly ( $\nabla$ tahamoly@hotmail.com )

Egyptian Atomic Energy Authority https://orcid.org/0000-0001-5246-2168

Heba Kahil

Ain Shams University Faculty of Science

\section{Research}

Keywords: SPIONs (superpara-iron oxide), thermoresponsive polymer, hyperthermia, PARP inhibitor, NIPAM

Posted Date: March 17th, 2021

DOI: https://doi.org/10.21203/rs.3.rs-295938/v1

License: (c) (i) This work is licensed under a Creative Commons Attribution 4.0 International License. Read Full License 


\title{
Magnetic thermoresponsive nanocomposite for targeted PARP-1 in colorectal adenocarcinoma, an approach for tumor dual therapy
}

\author{
Alaa AL-Rahman Gamal, El-Sayed Mahmoud El-sayed, Tarek El-Hamoly, Heba Kahil
}

\section{Authors:}

\section{1- Alaa AL-Rahman Gamal}

Biophysics group, Physics Department, Faculty of Science, Ain Shams University, Cairo Egypt. E-mail: alaaalrahmansci@gmail.com

\section{2-Prof. El-Sayed Mahmoud El-sayed}

Biophysics group, Physics Department, Faculty of Science, Ain Shams University, Cairo Egypt. E-mail: elsayedmahmoud20@ hotmail.com

\section{3- Dr. Tarek El-Hamoly}

Drug Radiation Research Department, National Center for Radiation Research and Technology, Egyptian Atomic Energy Authority, Cairo, Egypt

Cyclotron Project, Nuclear Research Centre, Egyptian Atomic Energy Authority, Cairo, Egypt.

*Corresponding Author: E-mail: tahamoly@ hotmail.com,

Postal Code: 11787, PO box 29, Nasr City, Cairo, Egypt.

\section{4- Dr. Heba Kahil}

Biophysics group, Physics Department, Faculty of Science, Ain Shams University, Cairo Egypt. E-mail: hebakahil@sci.asu.edu.eg 


\section{Abstract}

Background: The current study presents a bimodal therapeutic platform for cancer treatment. Bimodal implies that the presented drug loaded core-shell structure is capable of elevating the tumor tissue temperature (hyperthermia) through the superparamagnetic iron oxide core and simultaneously release a Poly (ADP-ribose) polymerase-1(PARP-1)-modifying agent from the thermoresponsive shell. The capability of Superparamagnetic iron oxide nanoparticles (SPIONs) as successful hyperthermia agents is well established. Likewise, poly-n-isopropylacrylamide (PNIPAAm) is a widely used thermoresponsive polymer. Together, they constitute the magnetic thermoresponsive nanocomposite (MTN). To the authors knowledge, the combination of magnetic nanocomposites with PARP-1 modifying agents has not been investigated. Therefore, in this work, 5-aminoisoquinoline (5-AIQ) is loaded on the thermoresponsive polymer to constitute MTN.5AIQ.

Results: Structural characterization of the formed composite is studied via various experimental tools. The lower critical solution temperature (LCST) is determined by differential scanning calorimetry (DSC) method. The results confirm the formation of magnetic thermoresponstive nanocomposite (MTN) with excellent potential for hyperthermia. A high drug loading efficiency $(85.72 \%)$ is obtained with convenient temperature dependent drug release kinetics. Biocompatibility and cytotoxic efficacy are tested on an in vivo and in vitro colorectaladenocarcinoma models, respectively. MTN.5-AIQ administration exhibits normal hepatic and renal functions as well as lower toxic effect on normal tissue. In addition, the composite effectively inhibits Caco-2 cells viability upon incubation. 
Conclusions: Based on the obtained results, the proposed therapeutic platform can be considered as a novel, promising candidate as dual therapy for colorectal adenocarcinoma exhibiting a PARP1 overexpression.

Key words: SPIONs (superpara-iron oxide), thermoresponsive polymer, hyperthermia, PARP inhibitor, NIPAM

\section{Background}

Enormous interest has been focused on developing smart delivery vehicles capable of targeting and controlling the release of chemotherapeutic agents. Controlled drug release is very attractive as it overcomes various drawbacks of conventional chemotherapy. Limitations of using chemotherapy with subsequent adverse outcomes on healthy tissues can be attributed to incompatible pharmacokinetics as well as narrow therapeutic indices(Senapati, Mahanta, Kumar, \& Maiti, 2018),(Cho, Wang, Nie, Chen, \& Shin, 2008). Recently, the utilization of smart polymers showed great potential for controlling drug release when subjected to external stimuli such as temperature, PH, electric/magnetic field, light, etc.(Kost \& Langer, 2012),(Anderson, Burdick, \& Langer, 2004),(Xiong et al., 2011),(Priya James, John, Alex, \& Anoop, 2014). Among the various thermoresponsive polymers, poly-n-isopropylacrylamide (PNIPAAm) is the most extensively used candidate.

This paper reports the design of a core-shell drug loaded platform, in which SPIONs constitutes the core that acts as the heat source, and PNIPAAm acts as the thermoresponsive shell, together they constitute the core shell magnetic thermoresponsive nanocomposite (MTN). 5aminoisoquinoline (5-AIQ) acts as a PARP inhibitor loaded on MTN. This drug loaded magnetic thermoresponsive nanocomposite (MTN.5-AIQ) can be intravenously injected and targeted to the 
tumor site by a magnetic field gradient. An alternating magnetic field (AMF) then triggers heat production by the SPION cores-which concequently triggers drug release. The elevated temperature along with the chemotherapeutic agent are awaited to play synergistic roles in tumor treatment.

The thermoresponsive Poly(N-isopropylacrylamide) (PNIPAAm) is frequently used for drug delivery owing to its low critical solution temperature (LCST $\approx 32^{\circ} \mathrm{C}$ ); close to the human body temperature(Priya James et al., 2014),(Ward \& Georgiou, 2011). This polymer exhibits coilglobule phase transition when the temperature changes around the LCST of the polymer. At temperatures below its LCST, PNIPAAm becomes hydrophilic as it swells and extends in virtue of the intermolecular hydrogen bonds formed between polymer chains and water molecules. In contrast, above LCST, the polymer chain collapses, releases much of the water content and eventually shrinks. These reversible shrinking and water release of PNIPAAm are exploited for drug loading and release(Sun et al., 2004),(Schmaljohann, 2006).

SPIONs act as tiny antennae that generate heat upon exposure to alternating magnetic field (AMF) (Salimi, M., Sarkar, S., Saber, R. et al. (2018)). They exhibit superparamagnetic behavior at room temperature; they can be magnetized by applying magnetic field and the effect is abolished once the applied field is ceased (Gould, 2006). Heat dissipation from these superparamagnetic nanoparticles is caused by two relaxation mechanisms; either by the rotation of the moments within the particle (Néel relaxation) or by the physical rotation of the particle itself (Brownian or viscous loss) (Abenojar, Wickramasinghe, Bas-Concepcion, \& Samia, 2016) upon exposure to AMF. Néel $\left(\tau_{\mathrm{N}}\right)$ and Brownian $\left(\tau_{\mathrm{B}}\right)$ magnetic relaxation times of a particle are given by Equation 1 and Equation 2 respectively; where $\tau_{\mathrm{N}}$ is the Néel the relaxation time, $\tau_{\mathrm{B}}$ is the Brownian relaxation time, $\mathrm{V}_{\mathrm{m}}$ is the volume of the magnetic core, $\mathrm{K}$ is the anisotropy constant, $\mathrm{k}_{\mathrm{B}}$ is the 
Boltzmann constant, $\mathrm{T}$ is the absolute temperature, $f_{\circ}$ is an attempt frequency for changes in the dipole direction, $\eta$ is the viscosity of the carrier fluid and $V_{\text {hyd }}$ is the hydrodynamic volume of the particle.

$$
\begin{aligned}
\tau_{N} & =\frac{1}{f_{\circ}} \exp \left(\frac{K V_{m}}{K_{B} T}\right) \\
\tau_{B} & =\frac{3 V_{h y d}}{K_{B} T} \eta
\end{aligned}
$$

PARP-1 belongs to the superfamily of more than seventeen enzymes that catalyzes the transfer of ADP-ribose units from its substrate $\mathrm{NAD}^{+}$to several protein acceptors as single-strand break repair and base excision repair factors, which contribute to DNA repair (Watson, Whish, \& Threadgill, 1998),(Ba \& Garg, 2011). In general, PARP inhibitors act through competitive blocking of the $\mathrm{NAD}^{+}$binding domain of the enzyme(Virág \& Szabó, 2002); the effect which inhibits the repair of damaged DNA and facilitates apoptosis-dependent death of tumor cells (Threadgill, 2015). 5aminoisoquinoline (5-AIQ) is an active, water soluble inhibitor of Poly (ADP-ribose) polymerase1 (PARP-1) and adjunctly promotes radiotherapy and chemotherapy of various cancer types (Vinod, Chandra, \& Sharma, 2010),(Cuzzocrea et al., 2002). The elevated mortality associated with metastatic colon cancer is attributed to further development of resistant microenvironments towards current drugs. Latest chemotherapeutic protocols for colon cancer include DNAmodifying pharmaceuticals, like oxaliplatin or irinotecan, combined with 5-fluorouracil (Raftery \& Goldberg, 2010). Such treatment regimens are initially successful in numerous patients, but ultimately, the majority of them become resistant. A significant interpretation of this resistance in colon cancer is the frequent DNA repair mechanism-linked to high expression of PARPs enzymes(Nosho et al., 2006),(Sulzyc-Bielicka et al., 2012). Previous studies investigated the use of commercially available PARP-1 inhibitors like Olaparib alone or in combination with the chemotherapeutic agents was accepted as a promising candidate for treatment of colon cancer 
(Davidson, Wang, Aloyz, \& Panasci, 2013),(Augustine, Maitra, Zhang, Nayak, \& Goel, 2019). Magnetite coated with thermoresponsive polymer and its derivatives was previously synthesized for drug delivery and controlled drug release applications. Doxorubicin was loaded on the magnetite thermoresponsive nanocomposite and used as the anticancer model drug(Müller-Schulte \& Schmitz-Rode, 2006) (Akbarzadeh et al., 2012), (Zhang \& Misra, 2007), (Hegazy et al., 2017) (Fan, Li, Wu, Li, \& Wu, 2011),(Purushotham \& Ramanujan, 2010). In addition, indomethacin was loaded on thermo-responsive MNP nanoclusters grafted with poly(NIPAAm) and poly(NIPAAm-co-PEGMA) copolymers used as the anticancer model drug (Meerod, Rutnakornpituk, Wichai, \& Rutnakornpituk, 2015). The current work investigates the feasibility of loading 5-aminoioquinoline drug (5-AIQ) on the magnetic thermoresponsive polymer and its release kinetics.

\section{Results and discussion}

\section{Structure and morphology}

The X-ray diffraction (XRD) pattern of the iron oxide core is shown in Figure 1A. The obtained pattern shows a face centered cubic (FCC) structure, the peaks positioned at $2 \theta=29.942^{\circ}, 35.386^{\circ}$, $43.123^{\circ}, 57.019^{\circ}$ and $62.581^{\circ}$ correspond to reflections from the planes; (220), (311), (400), (511) and (440) respectively (Wang, Wei, \& Qu, 2013). These positions and their relative intensities are consistent with ICDD 890688 card (Wang et al., 2013). This confirms that the synthesized particles are single phase magnetite or maghemite. The calculated average crystallite for the obtained SPIONs size is $12.7 \mathrm{~nm}$ and the average lattice parameter is $8.39 \AA$.

The Fourier transform infrared spectroscopy (FTIR) spectrum of the magnetite $\left(\mathrm{Fe}_{3} \mathrm{O}_{4}\right)$ is shown in Figure 1B (lower plot in black). The $\mathrm{Fe}_{3} \mathrm{O}_{4}$ sample exhibits one intense peak at $550 \mathrm{~cm}^{-1} \doteqdot$ due to stretching vibration mode associated with the metal-oxygen absorption band ( $\mathrm{Fe}-\mathrm{O}$ bonds) in the $\mathrm{Fe}_{3} \mathrm{O}_{4}$ sample(Lesiak et al., 2019). There are less intense peaks at 1632 and $865 \mathrm{~cm}^{-1}$ resulting 
from the bending vibration of the $\mathrm{O}-\mathrm{H}$ in plane and out of plane bonds of water respectively (Lopez, González, Bonilla, Zambrano, \& Gómez, 2010) in addition to a broad peak centered at $3377 \mathrm{~cm}^{-1}$ due to the $\mathrm{O}-\mathrm{H}$ bond stretching vibrations of water (Coates, 2004). FTIR spectrum of SPION-PNIPAM sample is also shown in Figure 1B (upper plot in red). The spectrum illustrates the characteristic peaks of $\mathrm{Fe}_{3} \mathrm{O}_{4}$ and PNIPAAm. The peak at $550 \mathrm{~cm}^{-1}$ represents $\mathrm{Fe}-\mathrm{O}$ bond with no observed shift because the SPION-PNIPAAm is prepared after the magnetite is synthesized (post synthesis polymerization). The characteristic peaks at $1545 \mathrm{~cm}^{-1}$ and $1650 \mathrm{~cm}^{-1}$ represent the amide II ( $\mathrm{N}-\mathrm{H}$ bending) and amide I $(\mathrm{C}=\mathrm{O}$ stretching) vibrational mode found in NIPAAm respectively, the peaks at 1365 and $1395 \mathrm{~cm}^{-1}$ arise from bending vibration of isopropyl group $\mathrm{CH}\left(\mathrm{CH}_{3}\right)_{2}$ found in NIPAAm, the peak at $3300 \mathrm{~cm}^{-1}$ corresponds to secondary $\mathrm{N}-\mathrm{H}$ amide symmetric stretching vibration (Chou, Lai, Shih, Tsai, \& Lue, 2013),(Omer, Haider, \& Park, 2011), the peaks at $2972 \mathrm{~cm}^{-1}$ and $1460 \mathrm{~cm}^{-1}$ correspond to (C-H) stretching and bending vibration respectively (Coates, 2004), the peak at $1245 \mathrm{~cm}^{-1}$ corresponds to (C-N) bending vibration found in NIPAAm (Narain, 2010).

High transmission electron microscope (HRTEM) analysis shows the size and morphology of MTN. TEM micrograph of MTN in Fig. 1C reveals the spherical shape of MTN with core shell structure. The MNPs appears as dark spots coated with PNIPAM that constitutes the grayish layer as clarified by the arrows. The observed aggregation of the particles is a consequence of imaging under high vacuum conditions. The average diameter of magnetite was estimated with automated size distribution analysis software (image J). The size distribution curve of magnetite obtained from TEM micrographs shown in Fig. 1D. The magnetite diameter was determined to be $11 \mathrm{~nm}$, which is consistent with the size obtained from XRD data, suggesting each particle is a single crystal. Moreover, the statistical analysis of the particles reveals the narrow size distribution of the 
nanoparticles $(5-20 \mathrm{~nm})$. Selected area electron diffraction pattern is shown in Fig. 1E. Peak indexing-was performed using Equation 3; where $d$ is the interplanar spacing, $\mathrm{R}_{\mathrm{r}}$ is the ring radius, $\mathrm{Lf}_{\mathrm{f}}$ is the camera focal length and $\lambda$ is the wavelength of electron, and it is given by Equation 4 .

$d=\frac{\lambda}{R_{r}} L f$

$\lambda=\sqrt{\frac{1.505}{V}}$

For the (311) plane, the calculated d-value from SAED, XRD and standard d-values in literature (Zhang \& Misra, 2007),(Lesin, Koksharov, \& Khomutov, 2010) are 2.5340, 2.53454 and $2.53(\AA)$ respectively which confirms the face centered cubic structure of SPIONs.

Energy dispersive X-ray (EDX) spectrum of MTN is shown in Fig. 2A. The major peaks of Fe at $0.7,6.3,7 \mathrm{keV}$ correspond- to the binding energy of $\mathrm{Fe}(\mathrm{L} \alpha, \mathrm{K} \alpha$ and $\mathrm{K} \beta$ respectively) (Zayed, Imam, Ahmed, \& El Sherbiny, 2017). The presence of nitrogen peaks confirms the coating of magnetite with the poly N, isopropylacrylamide (Mutharani, Ranganathan, \& Chen, 2019).

The polymer content of magnetic thermoresponsive nanocomposite (MTN) was determined using TGA analysis. TGA thermogram estimates the weight loss occurring in the sample upon increasing the temperature from room temperature to $850^{\circ} \mathrm{C}$ as shown in Fig. $2 \mathrm{~B}$. The thermogram shows that weight loss occurred in two steps; one below $200^{\circ} \mathrm{C}$ due to loss of water, the other occurred in the range from 200 to $600^{\circ} \mathrm{C}$. The latter loss was attributed to the degradation of the side chain functional group and back bone structure of the PNIPAM (Purushotham \& Ramanujan, 2010). The results show that the amount of PNIPAAm in MTN is 5.08\%.

\section{Thermal response}


The LCST for NIPAAM is studied via the turbidity test. The transmittance versus temperature is shown in Fig. 3A. Diminished transmission occurred at $33{ }^{\circ} \mathrm{C}$, rendering this temperature as the LCST. This result is consistent with the LCST values reported in literature; between $30-34{ }^{\circ} \mathrm{C}$ (Priya James et al., 2014)'(Ward \& Georgiou, 2011) '(Schmaljohann, 2006). It is worth noticing that, the turbidity test could not be conducted for MTN sample in which magnetite is the major constituent ( 91.6\%). For this purpose, DSC was utilized and gave an endothermic peak at $48^{\circ} \mathrm{C}$ as shown in Fig. 3B, designating it as the LCST. A slight increase in LCST of the polymer upon encapsulating magnetite has been reported previously(Dionigi et al., 2014),(Pich, Bhattacharya, Lu, Boyko, \& Adler, 2004),(Rubio-Retama et al., 2007) and was explained on the basis of the steric hindrance of the magnetite core to the collapse of the polymeric chain at the phase transition temperature. Herein, the shift of LCST on MTN is higher than expected. This observation may be attributed to the high magnetite concentration as well as utilization of aluminum oxide $\left(\mathrm{Al}_{2} \mathrm{O}_{3}\right)$ as the reference in the DSC measurement rather than the magnetite. Another influencing factor may be the high heating rate compared to the rate of collapse of the polymer chains.

\section{Magnetic and specific absorption rate (SAR) measurements of magnetic core}

The magnetization curve of magnetite $\left(\mathrm{Fe}_{3} \mathrm{O}_{4}\right)$ is shown in Fig. 3C. The curve reveals the superparamagnetic behavior of $\mathrm{Fe}_{3} \mathrm{O}_{4}$ at room temperature with inconspicuous value of remnant magnetization. The saturation magnetization of is $35.412 \mathrm{emu} / \mathrm{g}$ which is less than the saturation magnetization of bulk magnetite (92 emu/gm and 74-80 emu/gm) for maghemite (Shokrollahi, 2017). The result is consistent with the fact that the saturation magnetization decreases with size. As the particle size decreases, the surface to volume ratio increases and in turn, the magnetically dead layer fraction increases because of the canted and disordered spins forming a magnetically 
dead layer on the surface of the nanoparticles (Khairy, 2013). Likewise, the coercivity decreases with decreasing size below the critical size, which is consistent with previous theoretical estimations (Li et al., 2017),(Huber, 2005) The low values of coercive field (36.3 emu/g) and remanent magnetization $(0.93694 \mathrm{G})$ unveil that the sample is superparamgnetic nature of the sample at room temperature. Slightly lower values of saturation magnetization $(32.74 \mathrm{emu} / \mathrm{g})$ is obtained for MTN due to the non-magnetic polymer layer. It is worth noticing that the decrease in magnetization is consistent with the contribution of PNIPAM in the MTN structure as obtained from the TGA analysis. Coercive field and remanent magnetization are $34.522 \mathrm{G}$ and $0.83349 \mathrm{emu} / \mathrm{g}$ denoting a superparamagnetic behavior as well.

Assessment of specific absorption rate of SPIONs was performed by exposing the sample to alternating magnetic field (AMF) of strength equal to $9.4 \mathrm{kA} / \mathrm{m}$ and frequency of $198 \mathrm{kHz}$ obtained by the induction heater- Fig. 3D shows the temperature rise with time curve for two concentrations of magnetite colloid ( 3 and $7 \mathrm{mg} / \mathrm{ml}$ ) exposed to AMF. The field intensity and the operating frequency are within the acceptable range; concurring the patients-safety regulations for respective clinical application (Spirou, Basini, Lascialfari, Sangregorio, \& Innocenti, 2018). The calculated SAR values for the two-colloid concentrations (3 and $7 \mathrm{mg} / \mathrm{ml}$ ) are 70.69 and $78.91 \mathrm{~W} / \mathrm{g}$ respectively. This minor increase of SAR values upon increasing the concentration has been reported in literature (Piñeiro-Redondo et al., 2011) as being attributed to increasing the magnetic dipolar interactions between the particles. Even at the low concentration $(3 \mathrm{mg} / \mathrm{ml})$, the therapeutic temperature $\left(42^{\circ} \mathrm{C}\right)$ was reached after only 4 minutes of exposure.

\section{Drug loading and release kinetics}

Magnetic thermoresponsive nanocomposite (MTN) sample was loaded with 5-aminoisoquinoline (5-AIQ) by resuspension of MTN in four different concentrations of the drug as listed in Table 
S1. MTN.5-AIQ samples were separated by a strong magnet then the residual concentration of 5AIQ in the supernatants were quantified using High performance liquid chromatography (HPLC) analysis to measure the amount of residual drug. The HPLC chromatogram of 5-AIQ is shown in Figure S1A. Table 1 illustrates the value of drug loading efficiency of the samples and Fig. 4A illustrates the results. It was noticed that the drug loading efficiency increased as the concentration of feed drug increase and sample MTN.5-AIQ.4 has the highest drug loading capacity. Based on these results, the drug release kinetics were studied for sample, MTN.5-AIQ.4.

After incubation of MTN.5AIQ.4 sample at five temperatures - 35, 37, ,39, 41, and $43^{\circ} \mathrm{C}$ - for 30 minutes, the solution was separated by strong magnet and the supernatant was analyzed by UVvisible spectrophotometer. As shown in Fig. 4Bthe drug release was tested at different temperatures and the maximum release of the 5-AIQ was at $39.5^{\circ} \mathrm{C}$. In addition, Fig. S1Bdisplays the drug release concentration at various temperatures analyzed by HPLC, which supports the findings obtained using UV-spectrophotometer and confirms that the maximum amount of drug is released at hyperthermia within the acceptable therapeutic range.

\section{Biocompatibility and toxicological parameters}

\section{Kidney and liver functions}

Serum levels of creatinine, uric acid, glutamic pyruvic transaminase (GPT) and glutamic oxaloacetic transaminase (GOT) were evaluated for the control, cisplatin-treated and MTN.5-AIQtreated groups. Cisplatin impaired the renal function as is apparent from the significantly higher serum creatinine level $(\mathrm{p}<0.05)$ compared with the control as shown in Fig. 5A. the renal dysfunction induced by cisplatin was previously depicted in literature (Wu et al., 2020). The serum creatinine and uric acid levels of the MTN.5AIQ-treated group, however, are not significantly different from those of the control group as illustrated in Fig. 5A\&B; proving the biocompatibility 
of MTN.5-AIQ. The significant $(\mathrm{P}<0.05)$ elevation of serum level of GPT for the cisplatin group compared to control refers to the hepatotoxicity of cisplatin. On the other hand, the administration of MTN.5-AIQ did not produce any significant changes in liver function compared to the control as shown in Fig. 5C\&D. This result proves the biocompatibility of MTN.5-AIQ.

\section{Histopathology examination}

Upon cisplatin administration, a marked congestion and atrophy of glomeruli are observed in mice kidneys of cisplatin-treated group compare to normal (Fig. 6. A-C). Furthermore, liver histopathological abnormalities are detected, marked by swelling and vascular degeneration in hepatocytes (Fig. 6. I\&J) comparable with normal control. These observations confirming the nephrotoxicity and hepatotoxicity of cisplatin (Wu et al., 2020). In MTN.5-AIQ-treated group, normal renal and collecting tubules are shown in Fig. 6 (E-F), only slight congestion can be detected in the interstitial blood vesicles. As for hepatotoxicity examination, the livers of MTN.5AIQ -treated mice shows normal histopathological pictures with slight congestion in portal veins

with normal bile ductuli (Fig. 6. K). Such results supporting the biocompatibility of MTN.5-AIQ encouraged by undetectable toxicity of the examined organ applied for histological study.

\section{Cytotoxic effect of MTN.5-AIQ on colorectal adenocarcinoma}

The cytotoxicity of MTN and MTN.5-AIQ was studied on Caco-2 cells as shown in Fig. 7 and Figure S2. No significant cytotoxicity is induced neither by MTN nor by MTN.5-AIQ on Caco-2 cells up to $6 \mathrm{mg} / \mathrm{ml}$. Upon further increasing the concentration, the cytotoxicity of MTN increased. Chang et al investigated the cytotoxicity of magnetite nanoparticles on BHK-21 cells, concluding that there was no cytotoxic effect of iron at a concentration up to $100 \mu \mathrm{g} / \mathrm{mL}$ incubated for $24 \mathrm{~h}$ (Chang et al., 2016). In parallel, below $5 \mathrm{mg} / \mathrm{ml}$ concentration of PNIPAM polymer did not affect the cell survival. Such sublethal dose range were investigated by Vihola and his colleagues on two 
human cell lines; intestinal Caco-2 cell line and bronchial Calu-3 (Vihola, Laukkanen, Valtola, Tenhu, \& Hirvonen, 2005). As shown in the present results, the hyperthermia studies proved that low concentrations of magnetite, around $3 \mathrm{mg} / \mathrm{ml}$, can cause significant rise in temperature in a very short time; the phenomenon that trigger the 5-AIQ release. These two factors; hyperthermia and thermally triggered-drug release are aimed to play synergistic effects in treatment of metastatic colon cancer without any aggravated response toward healthy tissues.

\section{Conclusions}

In this work, the smart nanocomposite (MTN.5-AIQ) was successfully prepared with superior properties; high therapeutic temperature could be attained with considerably low concentration of SPIONs representing the magnetic core of the composite. The polymeric shell showed high efficiency in up taking the drug with convenient release kinetics at the therapeutic temperature range. In addition, MTN.5-AIQ showed good in vivo biocompatibility whereas, it caused antineoplastic effect for Caco-2 cell lines. These findings render this genuine loading of 5-AIQ on a thermoresponsive nanocomposite based on pNIPAAM and SPIONs a promising candidate of magnetic-based dual therapy for colorectal adenocarcinoma.

\section{Methods}

\section{Chemicals}

Ferric chloride hexahydrate $\left(\mathrm{FeCl}_{3} .6 \mathrm{H}_{2} \mathrm{O}, 97 \%\right)$, ferrous chloride Tetrahydrate $\left(\mathrm{FeCl}_{2} .4 \mathrm{H}_{2} \mathrm{O}\right.$, 98\%), sodium hydroxide pellets $(\mathrm{NaOH}, 98 \%)$ and ammonium persulfate (APS, 98\%) were purchased from LOBA CHEMIE PVT.LTD. While, N, isopropylacrylamide monomer (NIPAM, 97\%), N-methylene bisacrylamide (MBA ,99\%), N,N,N',N'Tetramethylethylenediamine (TEMED ,99\%) and 5-Aminoisoquinoline (5-AIQ) and Phosphate buffer saline (PBS) were purchased from 
Sigma Aldrich. Caco-2 cell lines were purchased from the Cell Bank of Egyptian company for production of vaccine, sera and drugs (VACSERA) (Cairo, Egypt). (RPMI) medium, Methylthiazolyldiphenyl-tetrazolium bromide (MTT) and Dimethyl sulfoxide (DMSO) were obtained from Sigma-Aldrich, St. Louis, MO, USA. All used chemicals are analytical grade.

\section{Synthesis of magnetite $\left(\mathrm{Fe}_{3} \mathrm{O}_{4}\right)$ nanoparticles}

Colloidal magnetite nanoparticles were prepared by the co-precipitation method. Briefly, $4.44 \mathrm{~g}$ of ferric chloride hexahydrate and $2.12 \mathrm{~g}$ of ferrous chloride tetra hydrate were dissolved in 150 $\mathrm{ml}$ of deionized water under magnetic stirring at $80^{\circ} \mathrm{C}$ for $15 \mathrm{~min}$; The $\mathrm{pH}$ of the solution was adjusted to 13 by addition of $10 \mathrm{M}$ sodium hydroxide solution. After another 15 minutes of stirring at $80^{\circ} \mathrm{C}$, the black precipitate (iron oxide nanoparticles) was formed. The precipitate was separated by strong magnet and washed several times with distilled water. Finally, these nanoparticles were dried under vacuum at room temperature overnight. The obtained MNPs powders were used for synthesis of magnetic thermoresponsive nanocomposite based on iron oxide and PNIPAAM (MTN).

\section{Synthesis of Magnetic Thermoresponsive Nanocomposite (MTN)}

$\mathrm{N}$, isopropyacrylamide monomer was polymerized in the presence of magnetite by free radical polymerization reaction $66.4 \mathrm{ml}$ solution of magnetite nanoparticles $(0.1 \mathrm{M})$ was added to $56.9 \mathrm{ml}$ solution of NIPAM monomer $(0.28 \mathrm{M})$ and sonicated for $10 \mathrm{~min}$. The mixture was transferred to a magnetic stirrer, during stirring, $4.74 \mathrm{ml}$ of the crosslinker MBA solution $(0.01 \mathrm{M})$ and $0.95 \mathrm{ml}$ of the initiator APS $(0.27 \mathrm{M})$ were added to the mixture. Afterwards, $1.8 \mathrm{ml}$ TEMED was added to the final solution. Stirring was continued for 20 minutes and the solution was left without disturbance for further 2 hours. The mixture was centrifuged at $13000 \mathrm{rpm}$ to collect the magnetic thermoresponsive nanocomposites (MTN) and washed several times with deionized water. MTN 
was dried in vacuum at room temperature for 24 hours and subsequently used for drug loading and further characterization.

\section{Characterization}

XRD pattern for magnetite nanoparticles was obtained by using an X-ray diffractometer (Philips X,pert MPD) with $\mathrm{CuK} \alpha$ radiation $\lambda=1.5418 \AA$. The crystallite size $(\mathrm{T})$ of the sample was calculated by Scherrer (Equation 5 ) (Sharma, Bisen, Shukla, \& Sharma, 2012); where $\beta$ is the width of the peak at half maximum intensity for a specific plane with miller indices $h$, $k$, and 1 ,whereas, $\mathrm{C}$ is the shape factor (taken as 0.9 ), $\lambda$ is the wavelength of the incident $\mathrm{X}$-ray and $\theta$ is the half angle between the incident and diffracted beams $(2 \theta)$ in radians. The lattice parameter was calculated by using Equation 6; where $\mathrm{d}_{\mathrm{hkl}}$ is the interplanar spacing, and $a$ is the lattice parameter.

$T=\frac{C \lambda}{\beta \cos \theta}$

$d_{h k l}^{2}=\frac{a^{2}}{h^{2}+k^{2}+l^{2}}$

FTIR spectra of magnetite and magnetic thermoresponsive nanocomposite samples, dispersed in $\mathrm{KBr}$ pellets, were obtained using FTIR (Nicolt 6700 at $4 \mathrm{~cm}^{-1}$ resolution). The morphology of magnetic thermoresponsive nanocomposites (MTN) was studied using high transmission electron microscope (HRTEM, JEM-2100, JEOL). The elemental composition of magnetic thermoresponsive nanocomposite (MTN) was determined using EDX spectroscopy (OXFORD INCA Penta FETX3- England). The polymer content in the magnetic thermoresponsive nanocomposite (MTN) was determined by thermogravimetric analyzer (TGA, SDT Q600 TA, USA) in the temperature range from room temperature to $850{ }^{\circ} \mathrm{C}$ at a heating rate of $10^{\circ} \mathrm{C} \min ^{-1}$ under nitrogen atmosphere. The LCST of the thermoresponsive polymer (PNIPAAm) was studied by performing the turbidity test. In this test, the transmittance of visible light at $500 \mathrm{~nm}$ through $(5 \mathrm{mg} / \mathrm{ml})$ PNIPAAm solution was measured for thermo-stated samples at various temperature 
ranging from 25 to $60{ }^{\circ} \mathrm{C}$ using UV-visible spectrophotometer (UV-5100 spectrophotometer, Shanghai, China). The LCST of magnetic thermoresponsive nanocomposite (MTN) was estimated using differential scanning calorimeter (DSC, SDT Q600 TA, USA) in the temperature range from 25 to $70{ }^{\circ} \mathrm{C}$ at a heating rate of $5^{\circ} \mathrm{C} \mathrm{min}^{-1}$ under nitrogen atmosphere. Magnetic measurements of magnetic nanoparticles (MNPs) and magnetic thermoresponsive nanocomposite (MTN) samples were obtained by vibrating sample magnetometer (VSM; 9600-1 LDJ, USA) at room temperature. The potential of magnetic core to produce heat via relaxation losses is reflected on SAR values using an induction heater (EQ-SPG-6A-I, China at $198 \mathrm{kHz}$, and $9.4 \mathrm{kA} / \mathrm{m}$ ). A constant volume of the ferrofluid ( $4 \mathrm{ml}$ of 3 and $7 \mathrm{mg} / \mathrm{ml}$ solution of magnetite in water) was placed in a glass vial that was inserted in a Styrofoam jacket -as an insulator-and the temperature was measured by an alcohol thermometer. SAR was calculated by using Equation 7; where $\mathrm{c}_{\mathrm{i}}$ is the individual specific heat of water and glass vial that are 4.18 and $0.793 \mathrm{JK}^{-1} \mathrm{~g}^{-1}$ respectively, $\mathrm{m}_{\mathrm{i}}$ is the individual mass of water and glass vial; taken as 4 and 5.2758 grams respectively, $\frac{\Delta T}{\Delta t}$ is the initial slope of the timedependent temperature curve and mSPION is the mass of SPION in the solution in grams.

$S A R=\frac{\sum m_{i} c_{i}}{m_{S P I O N}} \frac{\Delta T}{\Delta t}$

\section{Drug loading and release}

MTN was allowed to swell in various concentrations of 5-AIQ, sonicated for 15 minutes, and transferred to shaking water bath in dark for 23 hours at room temperature. Drug loaded MTN (MTN.5-AIQ) was separated from the solution by a strong magnet and the supernatant was analyzed by (HPLC, YOUNGLIN-9100, South Korea). Isocratic separation method was carried out according to the following conditions: $\mathrm{RB}_{18}$ column; mobile phase: acetonitrile $0.8 \%$ : acetic acid (6:4); flow rate: $1.5 \mathrm{ml} / \mathrm{min}$; Peaks were separated at $\lambda=260 \mathrm{~nm}$. The drug concentration was 
calculated using calibration curve. The drug uptake by MTN and drug loading efficiency were calculated by Equation 8 and Equation 9, respectively.

drug uptake $=W_{\text {feed }}-W_{\text {free }}(8)$

drug loading efficiency $=\frac{W_{\text {feed }}-W_{\text {free }}}{W_{\text {feed }}} \times 100$

Where; $\mathrm{W}_{\text {feed }}$ the weight of drug in which the MTN swelled, $\mathrm{W}_{\text {free, }}$ the weight of drug in the supernatant. To determine the temperature at which the maximum drug release occurred, MTN.5AIQ sample was suspended in phosphate buffer saline $(\mathrm{PH}=7.4)$ and incubated at different temperatures $\left(35,37,39,41\right.$, and $\left.43^{\circ} \mathrm{C}\right)$ for $30 \mathrm{~min}$ and the supernatant was analyzed by UV-visible spectrophotometer at wavelength ranging from 200 to $250 \mathrm{~nm}$. The released drug concentrations were determined by calculating the area under the peak from 200 to $232 \mathrm{~nm}$.

\section{Biocompatibility and toxicological parameters}

Male Swiss albino mice weighing 25-31 g were kept at animal facility of Faculty of Science, Ain Shams University. The animals were housed in an air-conditioned facility with a 12-h light/dark cycle, allowed free access to food and water. Mice were humanely treated in accordance with the ARRIVE guidelines for animal care. All experimental procedures were approved by the Ain Shams University Research Ethics Committee.

Fifteen mice were randomly divided into three groups. The first group was i.p. injected with saline and served as sham-operated control, the second one administered a single dose of cisplatin $(15 \mathrm{mg} / \mathrm{kg})$ as a positive control (cisplatin-treated group). The last group administered a single intraperitoneal injection of (MTN.5-AIQ) (5mg/Kg). All mice were then euthanized and blood samples were collected from the heart and sera form different groups were separated by centrifugation $(1500 / 10 \mathrm{~min})$ and kept at $-20{ }^{\circ} \mathrm{C}$ until the time of analysis. The kidney and liver 
tissue samples were collected and fixed in $10 \%$ buffered neutral formalin for further histopathological studies.

\section{Kidney and liver functions}

Renal functions were evaluated by measuring serum creatinine and uric acid according to manufacturer's instructions using commercial calorimetric kits (Bio-diagnostic Co., Cairo, Egypt). Hepatic functions were evaluated by measuring serum glutamic oxaloacetic transaminase (GOT) and glutamic pyruvic transaminase (GPT) according to manufacturer's instructions (Biodiagnostic Co., Cairo, Egypt).

\section{Histological examinations}

Kidney and liver samples obtained from different experimental groups were fixed in $10 \%$ buffered neutral formalin. The samples were then routinely dehydrated in graded series of ethanol, cleared in xylol and mounted in molten paraplast at $58-62^{\circ} \mathrm{C}$. Paraffin sections of about $4 \pm 5 \mu \mathrm{m}$ were obtained, stained with H\&E stain (Page, 1983), and examined under light microscope (LICA, German, provided with HD camera).

\section{Cell culture and MTT assay}

Cryopreserved Caco- 2 cells were cultured in a humidified atmosphere $\left(5 \% \mathrm{CO}_{2}, 37^{\circ} \mathrm{C}\right)$ with RPMI-1640 Medium supplemented with 2\% fetal bovine serum (FBS) and $50 \mu \mathrm{g} / \mathrm{mL}$ gentamycin. Cells were passaged at 80-90\% confluency after trypsinization with pre-warmed trypsin-EDTA solution. The cytotoxicity of 5-AIQ, MTN and MTN.5-AIQ.4 samples was investigated on Caco2 cell lines by cell viability MTT assay. The experiment was conducted for determination of the IC50 (the concentration of the drug which causes 50\% cell death). The selected samples were twofold diluted in culture media. Cells were treated with $100 \mu \mathrm{l}$ of each sample and incubated for further 24 hours. Then, $20 \mu 1$ of MTT solution were added to each well and incubated for 1-5 hours. 
Finally, the produced formazan was dissolved in $200 \mu \mathrm{l}$ DMSO and the mean absorbance of three replicates was measured at $570 \mathrm{~nm}$.

\section{Statistical analysis}

All values are presented as means \pm SE. Statistical analysis of experimental data was performed using a one-way analysis of variance (ANOVA) followed by Donnett's multiple comparison test for comparing means from different treatment groups.

\section{List of abbreviations}

5-AIQ: 5-aminoisoquinoline

AMF: Alternating magnetic field

EDX: Energy dispersive $X$-ray

FCC: Face centered cubic

FTIR: Fourier transform infrared spectroscopy

GOT: Glutamic oxaloacetic transaminase

GPT: Glutamic pyruvic transaminase

HPLC: High performance liquid chromatography

HRTEM: High transmission electron microscope

LCST: Lower critical solution temperature

MTN: Magnetic thermoresponsive nanocomposite

PARP-1: Poly (ADP-ribose) polymerase-1

PNIPAAm: Poly-n-isopropylacrylamide

SAR: Specific absorption rate

SPIONs: Superparamagnetic iron oxide nanoparticles

XRD: X-ray diffraction 


\section{Declarations}

Ethics approval and consent to participate: Animal experiments were approved by the Ain Shams University Research Ethics Committee.

Consent for publication: The manuscript was approved for publication by Committee of scientific publication, Egyptian Atomic Energy Authority (195-07/2020).

Availability of data and materials: The datasets used in the present work are available from the corresponding author upon request.

Competing interests: All authors declare that this manuscript is original, has not been published before and is not currently being considered for publication elsewhere. The authors declare they have no competing interests as defined by Cancer nanotechnology, or other interests that might be perceived to influence the results reported in this paper.

Funding: This work was chiefly supported by the grants from Ain Shams University, Cairo, Egypt.

Author's Contributions: Conceptualization: AAG, TE, HK; EME; data curation: AAG, HK; formal analysis: AAG, TE, HK; funding acquisition: AAG, TE, HK; investigation: AAG, TE; methodology: AAG, TE, HK; writing original draft preparation: AAG, EME; writing - review and editing: all authors. All authors read and approved the final manuscript.

Acknowledgements: Magnetic and SAR measurements were conducted at Cyclotron Project, Nuclear Research Center, Egyptian Atomic Energy Authority, Egypt by Dr. Ismaeel Abdulrahim. 


\section{References}

Abenojar, E. C., Wickramasinghe, S., Bas-Concepcion, J., \& Samia, A. C. S. (2016). Structural effects on the magnetic hyperthermia properties of iron oxide nanoparticles. Progress in Natural Science: Materials International, 26(5): 440-448. https://doi.org/10.1016/j.pnsc.2016.09.004

Akbarzadeh, A., Zarghami, N., Mikaeili, H., Asgari, D., Goganian, A. M., Khiabani, H. K., ... Davaran, S. (2012). Synthesis, characterization, and in vitro evaluation of novel polymercoated magnetic nanoparticles for controlled delivery of doxorubicin. Nanotechnology, Science and Applications, 5(1): 13-25. https://doi.org/10.2147/NSA.S24328

Anderson, D. G., Burdick, J. A., \& Langer, R. (2004). Smart biomaterials. Science, 305(5692): 1923-1924. https://doi.org/10.1126/science.1099987

Augustine, T., Maitra, R., Zhang, J., Nayak, J., \& Goel, S. (2019). Sensitization of colorectal cancer to irinotecan therapy by PARP inhibitor rucaparib. Investigational New Drugs, 37(5): 948-960. https://doi.org/10.1007/s10637-018-00717-9

Ba, X., \& Garg, N. J. (2011). Signaling mechanism of poly(ADP-ribose) polymerase-1 (PARP1) in inflammatory diseases. American Journal of Pathology, 178(3):946-955. https://doi.org/10.1016/j.ajpath.2010.12.004

Chang, L., Liu, X. L., Fan, D. Di, Miao, Y. Q., Zhang, H., Ma, H. P., ... Fan, H. M. (2016). The efficiency of magnetic hyperthermia and in vivo histocompatibility for human-like collagen protein-coated magnetic nanoparticles. International Journal of Nanomedicine, 11:11751185. https://doi.org/10.2147/IJN.S101741

Cho, K., Wang, X., Nie, S., Chen, Z., \& Shin, D. M. (2008). Therapeutic nanoparticles for drug delivery in cancer. Clinical Cancer Research, 14(5):1310-1316. 
https://doi.org/10.1158/1078-0432.CCR-07-1441

Chou, F. Y., Lai, J. Y., Shih, C. M., Tsai, M. C., \& Lue, S. J. (2013). In vitro biocompatibility of magnetic thermo-responsive nanohydrogel particles of poly $(\mathrm{N}$-isopropylacrylamide-coacrylic acid) with Fe3O4 cores: Effect of particle size and chemical composition. Colloids and Surfaces B: Biointerfaces, 104: 66-74. https://doi.org/10.1016/j.colsurfb.2012.11.030

Coates, J. (2004). Encyclopedia of Analytical Chemistry -IInterpretation of Infrared Spectra, A Practical Approach. Encyclopedia of Analytical Chemistry, 1-23. Available via http://www3.uma.pt/jrodrigues/disciplinas/QINO-II/Teorica/IR.pdf. Accessed 14 Nov.2019.

Cuzzocrea, S., McDonald, M., Mazzon, E., Dugo, L., Serraino, I., Threadgill, M., ... Thiemermann, C. (2002). Effects of 5-aminoisoquinolinone, a water-soluble, potent inhibitor of the activity of poly (ADP-ribose) polymerase, in a rodent model of lung injury. Biochemical Pharmacology, 63: 293-304. https://doi.org/10.1016/S0006-2952(01)00864-4

Davidson, D., Wang, Y., Aloyz, R., \& Panasci, L. (2013). The PARP inhibitor ABT-888 synergizes irinotecan treatment of colon cancer cell lines. Investigational New Drugs, 31(2): 461-468. https://doi.org/10.1007/s10637-012-9886-7

Dionigi, C., Piñeiro, Y., Riminucci, A., Bañobre, M., Rivas, J., \& Dediu, V. (2014). Regulating the thermal response of PNIPAM hydrogels by controlling the adsorption of magnetite nanoparticles. Applied Physics A: Materials Science and Processing, 114(2): 585-590. https://doi.org/10.1007/s00339-013-7620-8

Fan, T., Li, M., Wu, X., Li, M., \& Wu, Y. (2011). Preparation of thermoresponsive and pHsensitivity polymer magnetic hydrogel nanospheres as anticancer drug carriers. Colloids and Surfaces B: Biointerfaces, 88(2): 593-600. https://doi.org/10.1016/j.colsurfb.2011.07.048 
Gould, P. (2006). Nanomagnetism shows in vivo potential. Nano Today, 1:34-39. https://doi.org/10.1016/S1748-0132(06)70115-3

Hegazy, M., Zhou, P., Wu, G., Wang, L., Rahoui, N., Taloub, N., ... Huang, Y. (2017).

Construction of polymer coated core-shell magnetic mesoporous silica nanoparticles with triple responsive drug delivery. Polymer Chemistry, 8(38): 5852-5864. https://doi.org/10.1039/c7py01179b

Huber, D. L. (2005). Synthesis, properties, and applications of iron nanoparticles. Small, 1(5):482-501. https://doi.org/10.1002/smll.200500006

Khairy, M. (2013). Synthesis, Characterization and Magnetic Properties of $\gamma$-irradiated and Unirradiated Magnetite Nanopowders. International Journal of Materials and Chemistry, 3(5):106-111. https://doi.org/10.5923/j.ijmc.20130305.04

Kost, J., \& Langer, R. (2012). Responsive polymeric delivery systems. Advanced Drug Delivery Reviews, 64(SUPPL.):327-341. https://doi.org/10.1016/j.addr.2012.09.014

Lesiak, B., Rangam, N., Jiricek, P., Gordeev, I., Tóth, J., Kövér, L., ... Borowicz, P. (2019). Surface Study of Fe3O4 Nanoparticles Functionalized With Biocompatible Adsorbed Molecules. Frontiers in Chemistry, 7(October). https://doi.org/10.3389/fchem.2019.00642

Lesin, V. I., Koksharov, Y. A., \& Khomutov, G. B. (2010). Magnetic nanoparticles in petroleum. Petroleum Chemistry, 50(2): 102-105. https://doi.org/10.1134/S0965544110020039

Li, Q., Kartikowati, C. W., Horie, S., Ogi, T., Iwaki, T., \& Okuyama, K. (2017). Correlation between particle size/domain structure and magnetic properties of highly crystalline $\mathrm{Fe} 3 \mathrm{O} 4$ nanoparticles. Scientific Reports, 7(1):1-4. https://doi.org/10.1038/s41598-017-09897-5

Lopez, J. A., González, F., Bonilla, F. A., Zambrano, G., \& Gómez, M. E. (2010). Synthesis and characterization of Fe3O4 magnetic nanofluid . Revista Latinoamericana de Metalurgia y 
Materiales ,. 30(1): 60-66. Available via

http://ve.scielo.org/scielo.php?script=sci_arttext\&pid=S0255-

69522010000100007\&lng=es\&nrm=iso.. Accessed 01 maech 2021.

Meerod, S., Rutnakornpituk, B., Wichai, U., \& Rutnakornpituk, M. (2015). Hydrophilic

magnetic nanoclusters with thermo-responsive properties and their drug controlled release.

Journal of Magnetism and Magnetic Materials, 392, 83-90.

https://doi.org/10.1016/j.jmmm.2015.05.022

Müller-Schulte, D., \& Schmitz-Rode, T. (2006). Thermosensitive magnetic polymer particles as contactless controllable drug carriers. Journal of Magnetism and Magnetic Materials, 302(1), 267-271. https://doi.org/https://doi.org/10.1016/j.jmmm.2005.05.043

Mutharani, B., Ranganathan, P., \& Chen, S. M. (2019). Highly sensitive and selective electrochemical detection of antipsychotic drug chlorpromazine in biological samples based on poly-N-isopropylacrylamide microgel. Journal of the Taiwan Institute of Chemical Engineers, 96, 599-609. https://doi.org/10.1016/j.jtice.2018.10.029

Narain, R. (2010). Engineered Carbohydrate-Based Materials for Biomedical Applications: Polymers, Surfaces, Dendrimers, Nanoparticles, and Hydrogels. Engineered CarbohydrateBased Materials for Biomedical Applications: Polymers, Surfaces, Dendrimers, Nanoparticles, and Hydrogels, 1720. https://doi.org/10.1002/9780470944349

Nosho, K., Yamamoto, H., Mikami, M., Taniguchi, H., Takahashi, T., Adachi, Y., ... Shinomura, Y. (2006). Overexpression of poly(ADP-ribose) polymerase-1 (PARP-1) in the early stage of colorectal carcinogenesis. European Journal of Cancer, 42(14), 2374-2381. https://doi.org/10.1016/j.ejca.2006.01.061

Omer, M., Haider, S., \& Park, S. Y. (2011). A novel route for the preparation of thermally 
sensitive core-shell magnetic nanoparticles. Polymer, 52(1), 91-97. https://doi.org/10.1016/j.polymer.2010.11.011

Page, D. L. (1983). Theory and Practice of Histological Techniques. In Human Pathology (Vol. 14). https://doi.org/10.1016/s0046-8177(83)80171-3

Pich, A., Bhattacharya, S., Lu, Y., Boyko, V., \& Adler, H.-J. P. (2004). Temperature-Sensitive Hybrid Microgels with Magnetic Properties. Langmuir, 20(24), 10706-10711. https://doi.org/10.1021/la040084f

Piñeiro-Redondo, Y., Bañobre-López, M., Pardiñas-Blanco, I., Goya, G., López-Quintela, M. A., \& Rivas, J. (2011). The influence of colloidal parameters on the specific power absorption of PAA-coated magnetite nanoparticles. Nanoscale Research Letters, 6(1), 1-7. https://doi.org/10.1186/1556-276X-6-383

Priya James, H., John, R., Alex, A., \& Anoop, K. R. (2014). Smart polymers for the controlled delivery of drugs - a concise overview. Acta Pharmaceutica Sinica B, 4(2), 120-127. https://doi.org/10.1016/j.apsb.2014.02.005

Purushotham, S., \& Ramanujan, R. V. (2010). Thermoresponsive magnetic composite nanomaterials for multimodal cancer therapy. Acta Biomaterialia, 6(2), 502-510. https://doi.org/10.1016/j.actbio.2009.07.004

Raftery, L., \& Goldberg, R. M. (2010). Optimal Delivery of Cytotoxic Chemotherapy for Colon Cancer. The Cancer Journal, 16(3); 214-219. https://doi.org/10.1097/PPO.0b013e3181ddc5ac

Rubio-Retama, J., Zafeiropoulos, N. E., Serafinelli, C., Rojas-Reyna, R., Voit, B., Lopez Cabarcos, E., \& Stamm, M. (2007). Synthesis and Characterization of Thermosensitive PNIPAM Microgels Covered with Superparamagnetic $\gamma$-Fe2O3 Nanoparticles. Langmuir, 
23(20), 10280-10285. https://doi.org/10.1021/la7009594

Salimi, M., Sarkar, S., Saber, R. et al. (2018). Magnetic hyperthermia of breast cancer cells and MRI relaxometry with dendrimer-coated iron-oxide nanoparticles. Cancer Nano 9, 7. https://doi.org/10.1186/s12645-018-0042-8

Schmaljohann, D. (2006). Thermo- and pH-responsive polymers in drug delivery. Advanced Drug Delivery Reviews, 58(15), 1655-1670. https://doi.org/10.1016/j.addr.2006.09.020

Senapati, S., Mahanta, A. K., Kumar, S., \& Maiti, P. (2018). Controlled drug delivery vehicles for cancer treatment and their performance. Signal Transduction and Targeted Therapy, 3(1), 1-19. https://doi.org/10.1038/s41392-017-0004-3

Sharma, R., Bisen, D. P., Shukla, U., \& Sharma, B. G. (2012). X-ray diffraction: a powerful method of characterizing nanomaterials. Recent Research in Science and Technology, 4(8), 7779. Available via: https://updatepublishing.com/journal/index.php/rrst/article/view/933 Accessed: 2 March 2021

Shokrollahi, H. (2017). A review of the magnetic properties, synthesis methods and applications of maghemite. Journal of Magnetism and Magnetic Materials, 426(July 2016), 74-81. https://doi.org/10.1016/j.jmmm.2016.11.033

Spirou, S. V., Basini, M., Lascialfari, A., Sangregorio, C., \& Innocenti, C. (2018). Magnetic hyperthermia and radiation therapy: Radiobiological principles and current practice. Nanomaterials, 8(6), 1-22. https://doi.org/10.3390/nano8060401

Sulzyc-Bielicka, V., Domagala, P., Hybiak, J., Majewicz-Broda, A., Safranow, K., \& Domagala, W. (2012). Colorectal cancers differ in respect of PARP-1 protein expression. Polish Journal of Pathology, 63(2), 87-92. Available via https://hal.archives-ouvertes.fr/hal00721624. Accessed 17 Sep. 2020.

Sun, T., Wang, G., Feng, L., Liu, B., Ma, Y., Jiang, L., \& Zhu, D. (2004). Reversible switching 
between superhydrophilicity and superhydrophobicity. Angewandte Chemie (International Ed. in English), 43(3), 357-360. https://doi.org/10.1002/anie.200352565

Threadgill, M. (2015). 5-Aminoisoquinolin-1-one (5-AIQ), a water-soluble inhibitor of the poly(ADP-Ribose)polymerases (PARPs). Current Medicinal Chemistry, 22, 3807 - 3829 https://doi.org/10.2174/0929867322666151002110602

Vihola, H., Laukkanen, A., Valtola, L., Tenhu, H., \& Hirvonen, J. (2005). Cytotoxicity of thermosensitive polymers poly( $\mathrm{N}$-isopropylacrylamide), poly(N-vinylcaprolactam) and amphiphilically modified poly(N-vinylcaprolactam). Biomaterials, 26(16), 3055-3064. https://doi.org/10.1016/j.biomaterials.2004.09.008

Vinod, K. R., Chandra, S., \& Sharma, S. K. (2010). Evaluation of 5-aminoisoquinoline (5-AIQ), a novel PARP-1 inhibitor for genotoxicity potential in vitro and in vivo. Toxicology Mechanisms and Methods, 20(2), 90-95. https://doi.org/10.3109/15376510903572870

Virág, L., \& Szabó, C. (2002). The Therapeutic Potential of Poly ( ADP-Ribose ). Pharmacological Reviews, 54(3), 375-429. https://doi.org/ 10.1124/pr.54.3.375.

Wang, B., Wei, Q., \& Qu, S. (2013). Synthesis and characterization of uniform and crystalline magnetite nanoparticles via oxidation-precipitation and modified co-precipitation methods. International Journal of Electrochemical Science, 8(3), 3786-3793. Available via https://www.researchgate.net/publication/281612957. Accessed 19 Sep. 2019

Ward, M. A., \& Georgiou, T. K. (2011). Thermoresponsive polymers for biomedical applications. Polymers, 3(3), 1215-1242. https://doi.org/10.3390/polym3031215

Watson, C. Y., Whish, W. J. D., \& Threadgill, M. D. (1998). Synthesis of 3-substituted benzamides and 5-substituted isoquinolin-1(2H)-ones and preliminary evaluation as inhibitors of poly(ADP-ribose)polymerase (PARP). Bioorganic and Medicinal Chemistry, 
6(6), 721-734. https://doi.org/10.1016/S0968-0896(98)00029-7

Wu, W. F., Wang, J. N., Li, Z., Wei, B., Jin, J., Gao, L., ... Meng, X. M. (2020). 7Hydroxycoumarin protects against cisplatin-induced acute kidney injury by inhibiting necroptosis and promoting Sox9-mediated tubular epithelial cell proliferation. Phytomedicine, 69(February), 153202. https://doi.org/10.1016/j.phymed.2020.153202

Xiong, W., Wang, W., Wang, Y., Zhao, Y., Chen, H., Xu, H., \& Yang, X. (2011). Dual temperature/pH-sensitive drug delivery of poly( $\mathrm{N}$-isopropylacrylamide-co-acrylic acid) nanogels conjugated with doxorubicin for potential application in tumor hyperthermia therapy. Colloids and Surfaces B: Biointerfaces, 84(2), 447-453. https://doi.org/10.1016/j.colsurfb.2011.01.040

Zayed, M. A., Imam, N. G., Ahmed, M. A., \& El Sherbiny, D. H. (2017). Spectrophotometric analysis of hematite/magnetite nanocomposites in comparison with EDX and XRF techniques. Journal of Molecular Liquids, 231, 288-295. https://doi.org/10.1016/j.molliq.2017.02.007

Zhang, J., \& Misra, R. D. K. (2007). Magnetic drug-targeting carrier encapsulated with thermosensitive smart polymer: Core-shell nanoparticle carrier and drug release response. Acta Biomaterialia, 3(6), 838-850. https://doi.org/10.1016/j.actbio.2007.05.011 


\section{Legends to figures:}

Fig. 1. (A) X-ray diffraction pattern for $\mathrm{Fe}_{3} \mathrm{O}_{4}$ nanoparticles, (B) FTIR spectra for $\mathrm{Fe}_{3} \mathrm{O}_{4}$ (lower curve) and $\mathrm{Fe}_{3} \mathrm{O}_{4}$-PNIPAAm (MTN) (upper curve). (C) TEM micrograph for $\mathrm{Fe}_{3} \mathrm{O}_{4}-\mathrm{PNIPAAm}$ (MTN), (D) size distribution histogram for $\mathrm{Fe}_{3} \mathrm{O}_{4}$ (nanoparticles), (E) SAED pattern of $\mathrm{Fe}_{3} \mathrm{O}_{4}-$ PNIPAAm (MTN).

Fig.2. (A) EDX pattern for $\mathrm{Fe}_{3} \mathrm{O}_{4}$-PNIPAAm (MTN). (B) TGA thermogram of the magnetic thermoresponsive nanocomposite (MTN).

Fig. 3. (A) Turbidity test for PNIPAAm showing the LCST of the polymer, (B) DSC of MTN showing the phase transition temperature of the nanocomposites. (C) Magnetization curves of $\mathrm{Fe}_{3} \mathrm{O}_{4}$ and MTN with inset showing the vanishingly small value of coercivity (D) Temperature time curve for $\mathrm{Fe}_{3} \mathrm{O}_{4}$ ferrofluids with two concentrations; $3 \mathrm{mg} / \mathrm{ml}$ and $7 \mathrm{mg} / \mathrm{ml}$; showing the initial (linear) rise.

Fig. 4. (A) Drug loading efficiency of MTN.5-AIQ samples, (B) 5-AIQ release profile of MTN.5AIQ.4 nanoparticles incubated at different temperatures. 5-AIQ; 5-aminoisoquinoline, MTN.5AIQ; magnetic thermoresponsive nanocomposite loaded with 5-aminoisoquinoline.

Fig.5. Effect of CIS (dose $=15 \mathrm{mg} / \mathrm{kg}$ ) and MTN.5AIQ (dose=5mg/kg) on kidney and liver functions: Serum (A) creatinine, (B) uric acid, (C) glutamic pyruvic transaminase (GPT)and (D) glutamic oxalic transaminase (GOT) were evaluated for the three experimental groups; CTRL, CIS and MTN.5-AIQ. Each value represents the mean $\pm \mathrm{SE}$ ( $\mathrm{n}=5$ mice per group), ${ }^{*}$ significantly different versus control group $(\mathrm{CTRL})(\mathrm{P}<0.05)$, ** significantly different versus control group $(\mathrm{P}<0.005)$, ****significantly different versus control group $(\mathrm{P}<0.0001)$. CTRL; control, CIS: cisplatin, MTN.5-AIQ; magneticthermoresponsive nanocomposite loaded with 5aminoisoquinoline.

Fig.6. (A) normal control of mouse kidney. (B-D) Pronounced histopathological abnormalities are seen in mice treated with cisplatin $(15 \mathrm{mg} / \mathrm{kg}$ body weight). (B) Congestion and partial atrophy of glomeruli in the cortex, (C) congestion and mild tubular degeneration in the cortico- medullary junction, (D) congestion and perarterial leucocytic aggregation in the medullary portion of the kidney. (E) Normal renal tubules in the cortico-medulry junction and normal collecting tubules (F) normal renal cortex be observed in the kidney of the MTN.5-AIQ-treated group. $(\mathrm{G} \& \mathrm{H})$ normal hepatic cords with normal hepatocytes in control group. (I\&J) Pronounced histopathological abnormalities are seen in mice treated with cisplatin $(15 \mathrm{mg} / \mathrm{kg}$ body weight. (I) Swelling and mild vascular degeneration in hepatocytes, $(\mathrm{J})$ congestion of both central and portal vein together with mononuclear aggregation. (K) Livers of MTN.5AIQ-treated mice shows nearly normal hepatic 
cords with normal hepatocytes and sinusoids. Scale bar=100 $\mu \mathrm{m}$. MTN.5-AIQ; magnetic thermoresponsive nanocomposite loaded with 5-aminoisoquinoline.

Fig.7. Cytotoxicity measurement of MTN and MTN.5-AIQ on Caco-2 cells; Caco-2 cells were incubated with different doses of either MTN unloaded or loaded composites. Twenty four hours later, cell viability was determined via MTT assay. MTN; magnetic thermoresponsive nanocomposite, MTN.5-AIQ; magnetic thermoresponsive nanocomposite loaded with 5aminoisoquinoline.

Table 1. Drug uptake and drug loading efficiency of MNC.5-AIQ samples

\begin{tabular}{|c|c|c|c|c|}
\hline Samples & $\begin{array}{c}\text { Free drug } \\
(\mathbf{m g})\end{array}$ & $\begin{array}{c}\text { Feed drug } \\
(\mathbf{m g})\end{array}$ & $\begin{array}{c}\text { Drug uptake } \\
(\mathbf{m g})\end{array}$ & $\begin{array}{c}\text { Drug loading } \\
\text { efficiency (\%) }\end{array}$ \\
\hline MNN.5-AIQ.1 & 1.6 & 5 & 3.4 & 68 \\
\hline MNN.5-AIQ.2 & 2.4 & 10 & 7.6 & 76 \\
\hline MNN.5-AIQ.3 & 6.268 & 20 & 13.732 & 68.67 \\
\hline MTN.5AIQ.4 & 4.284 & 30 & 25.716 & 85.72 \\
\hline
\end{tabular}




\section{Figures}
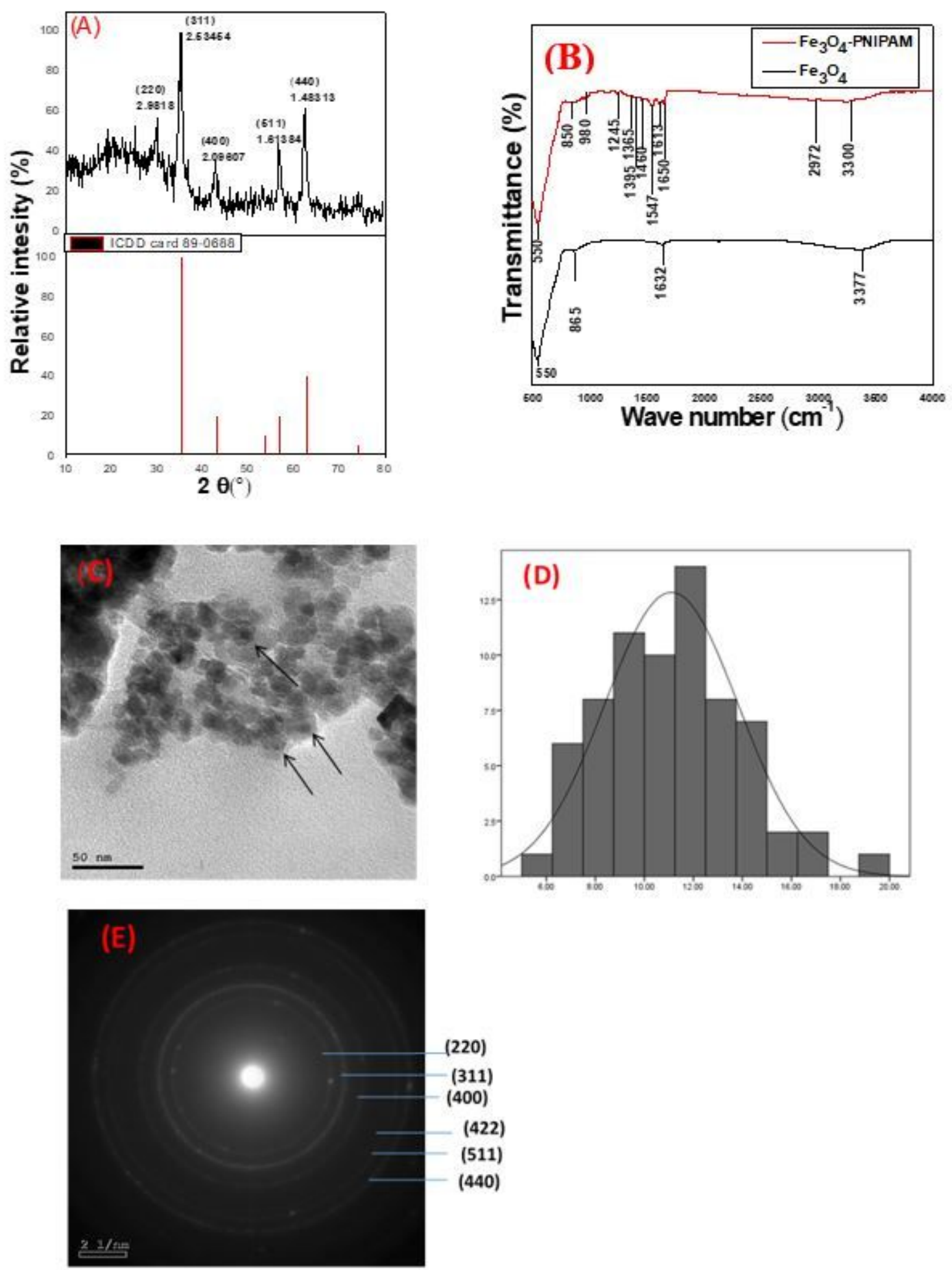

\section{Figure 1}

(A) X-ray diffraction pattern for Fe304 nanoparticles, (B) FTIR spectra for Fe304 (lower curve) and Fe304PNIPAAm (MTN) (upper curve). (C) TEM micrograph for Fe304-PNIPAAm (MTN), (D) size distribution histogram for Fe304 (nanoparticles), (E) SAED pattern of Fe304-PNIPAAm (MTN). 


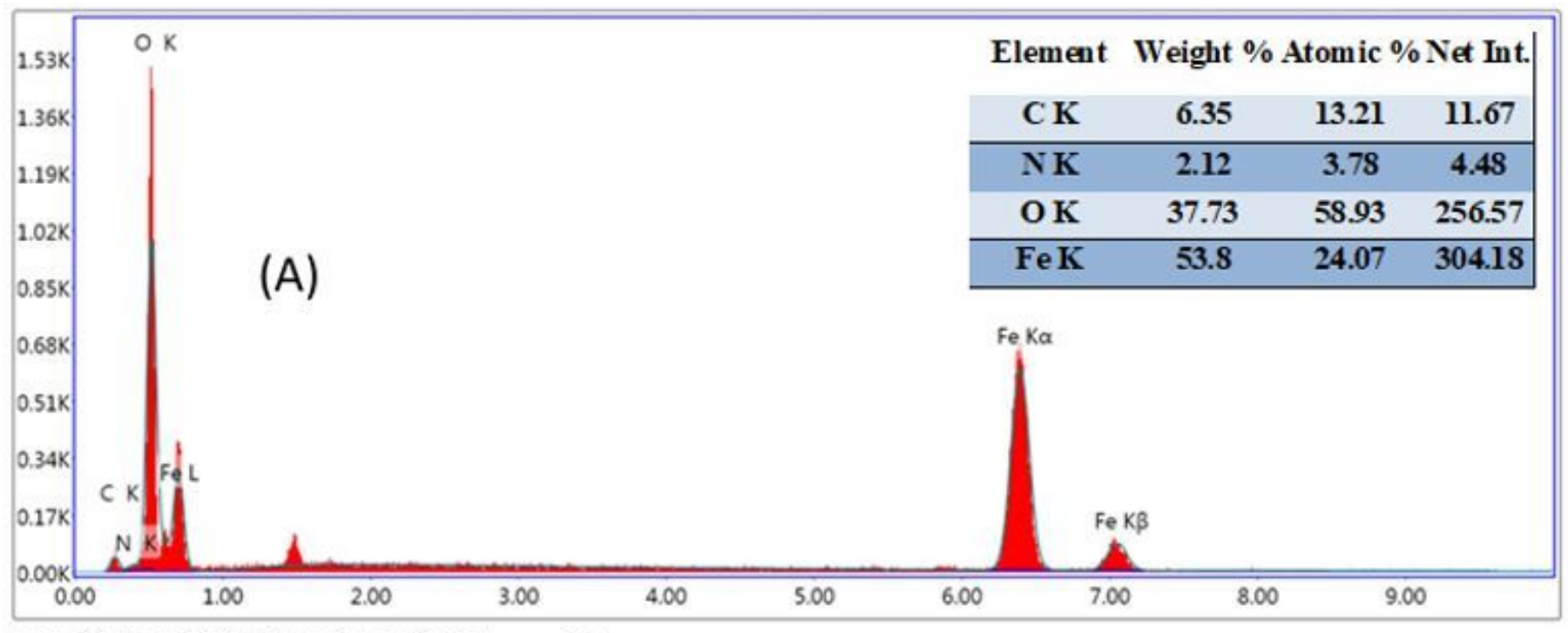

Lsec: 30.00 Cnts 0.000 keV Det: Octane Pro Det Reso

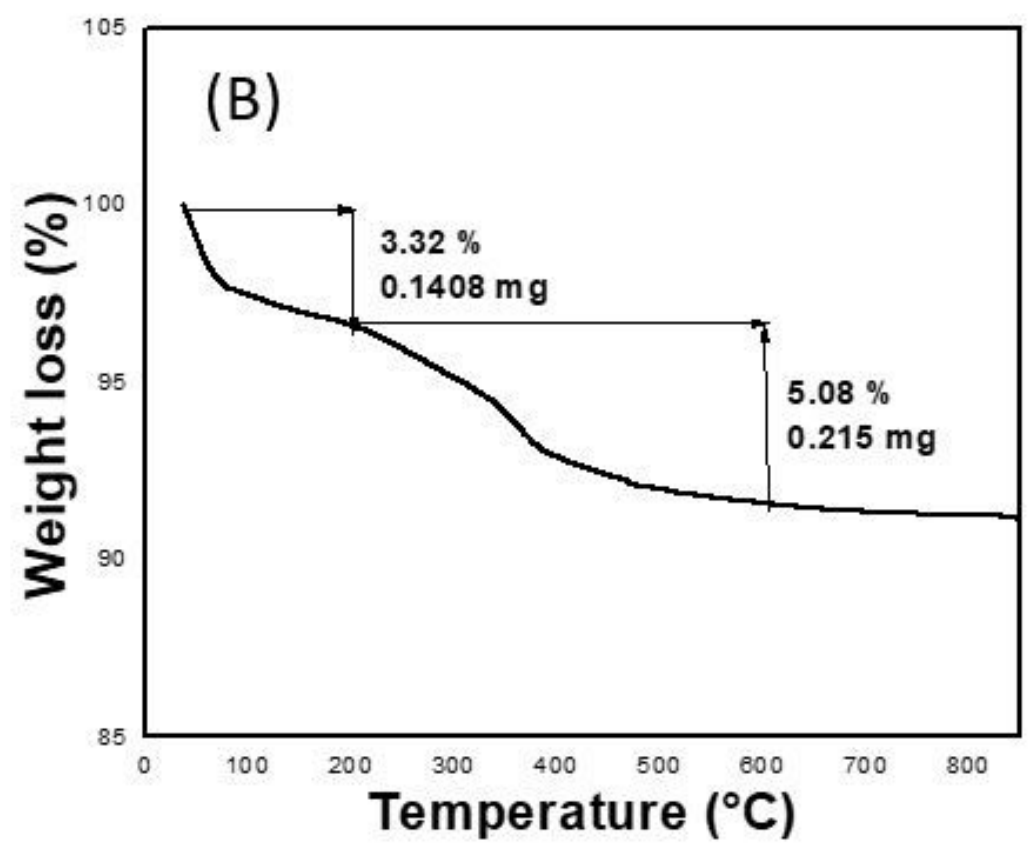

Figure 2

(A) EDX pattern for Fe304-PNIPAAm (MTN). (B) TGA thermogram of the magnetic thermoresponsive nanocomposite (MTN). 

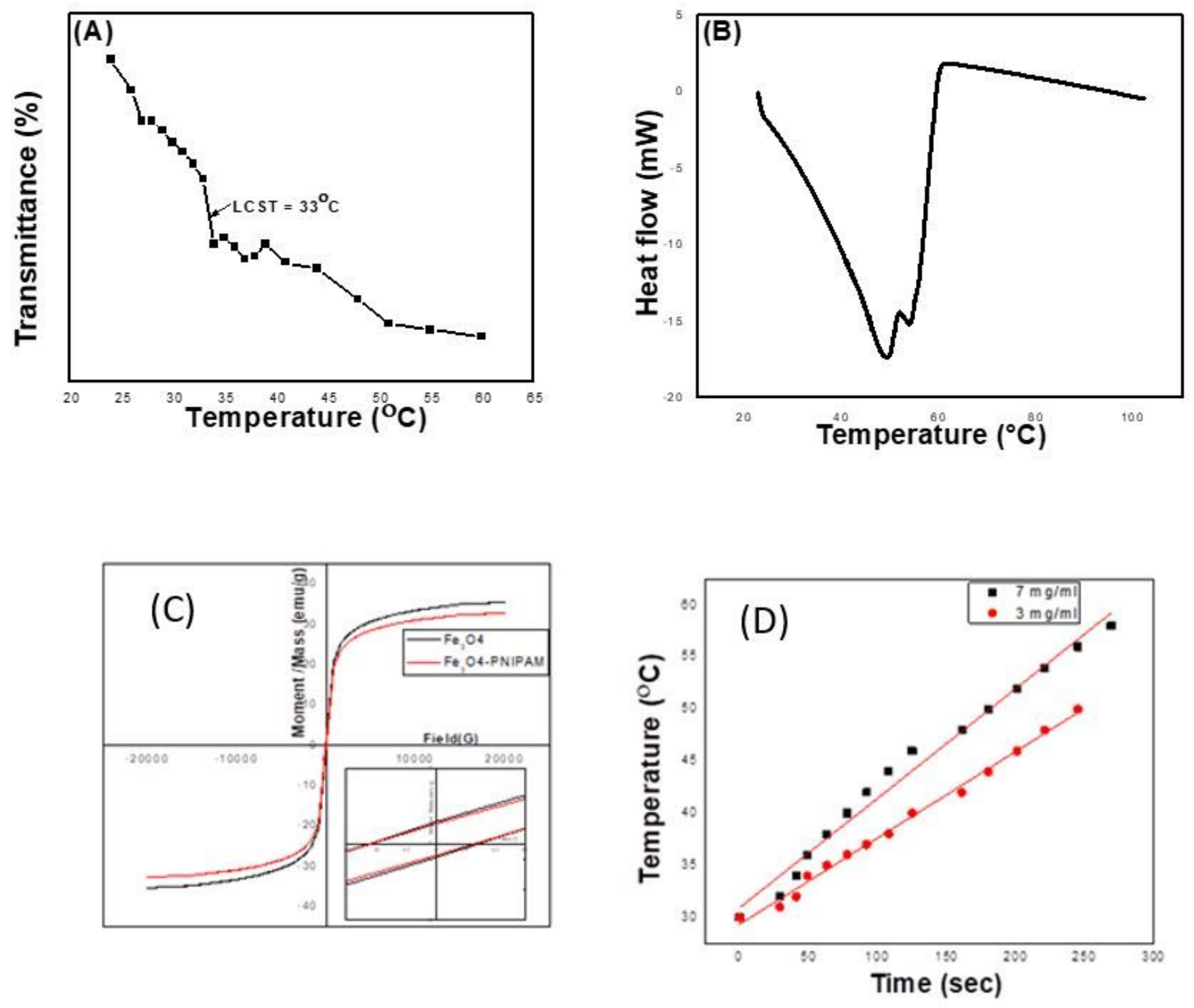

Figure 3

(A) Turbidity test for PNIPAAm showing the LCST of the polymer, (B) DSC of MTN showing the phase transition temperature of the nanocomposites. (C) Magnetization curves of Fe304and MTN with inset showing the vanishingly small value of coercivity (D) Temperature time curve for Fe304 ferrofluids with two concentrations; $3 \mathrm{mg} / \mathrm{ml}$ and $7 \mathrm{mg} / \mathrm{ml}$; showing the initial (linear) rise. 

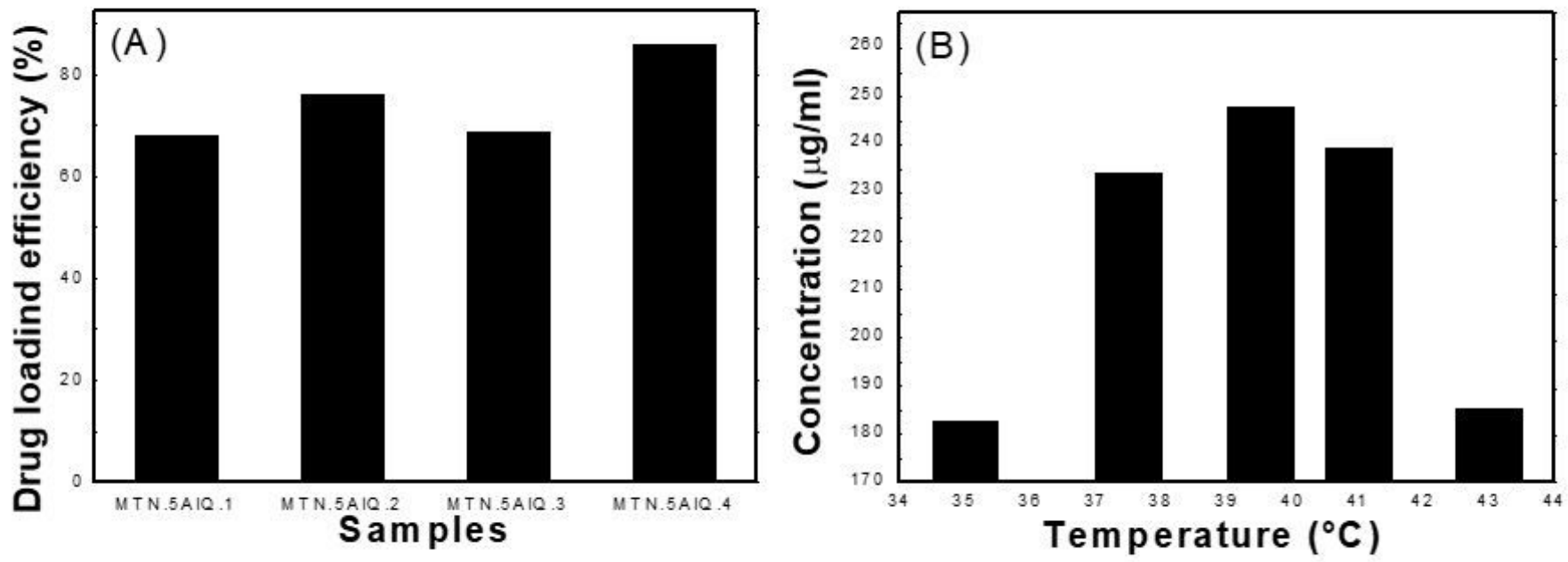

Figure 4

(A) Drug loading efficiency of MTN.5-AIQ samples, (B) 5-AIQ release profile of MTN.5-AIQ.4 nanoparticles incubated at different temperatures. 5-AIQ; 5-aminoisoquinoline, MTN.5-AIQ; magnetic thermoresponsive nanocomposite loaded with 5-aminoisoquinoline.
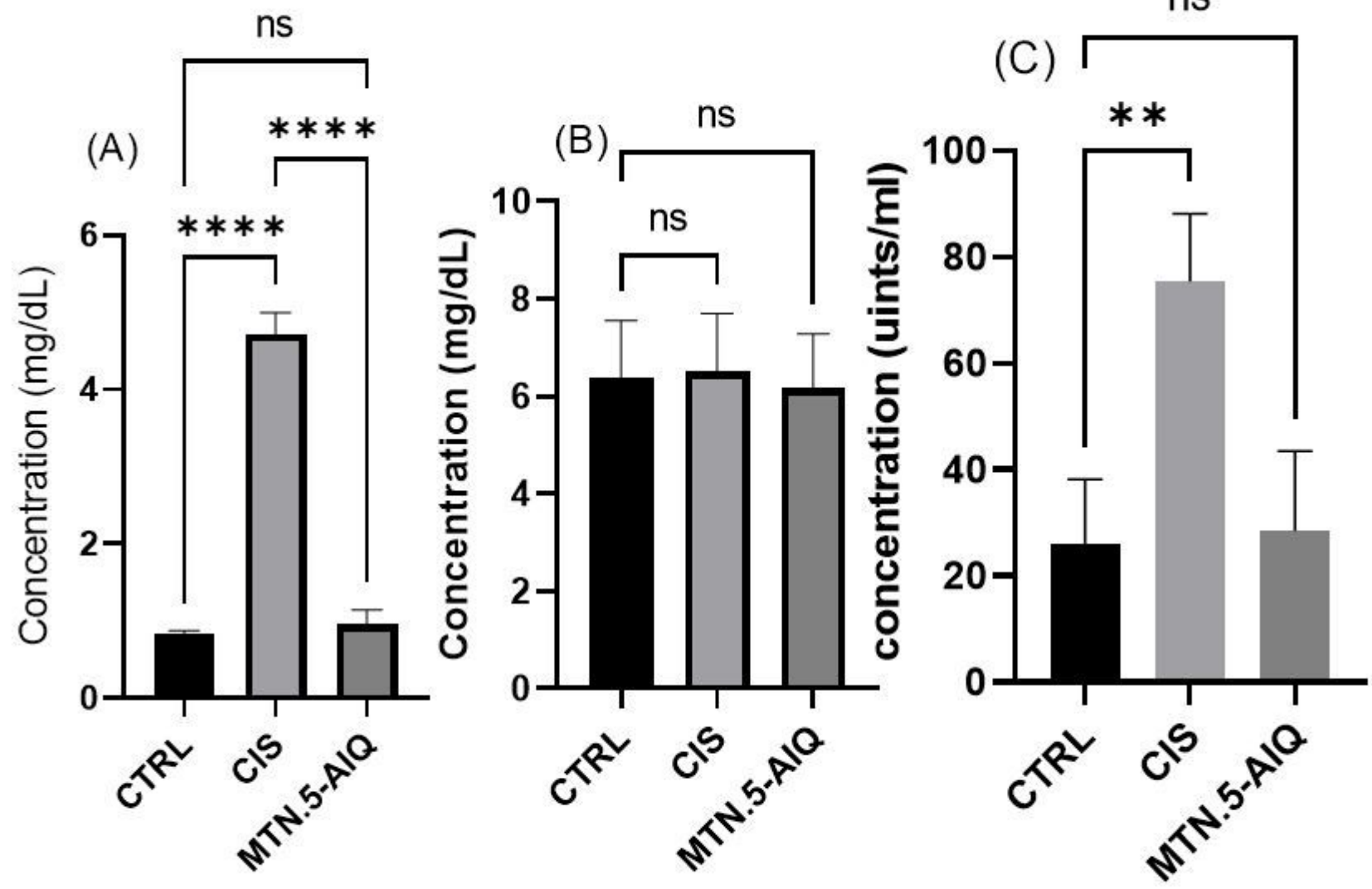


\section{Figure 5}

Effect of CIS (dose $=15 \mathrm{mg} / \mathrm{kg}$ ) and MTN.5AIQ (dose $=5 \mathrm{mg} / \mathrm{kg}$ ) on kidney and liver functions: Serum (A) creatinine, (B) uric acid, (C) glutamic pyruvic transaminase (GPT) and (D) glutamic oxalic transaminase (GOT) were evaluated for the three experimental groups; CTRL, CIS and MTN.5-AIQ. Each value represents the mean $\pm S E$ ( $n=5$ mice per group), ${ }^{*}$ significantly different versus control group (CTRL) $(P<0.05)$, ** significantly different versus control group $(P<0.005),{ }^{* * * *}$ significantly different versus control group $(P<0.0001)$. CTRL; control, CIS: cisplatin, MTN.5-AIQ; magneticthermoresponsive nanocomposite loaded with 5-aminoisoquinoline.
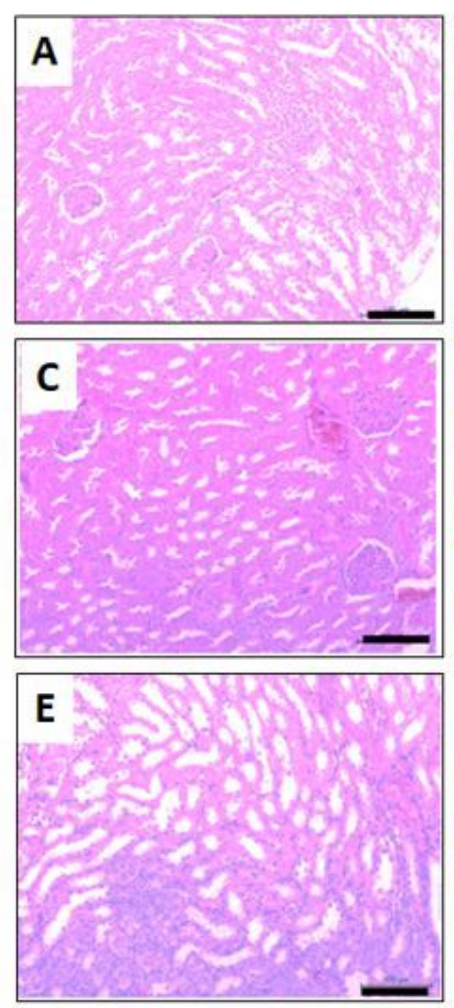
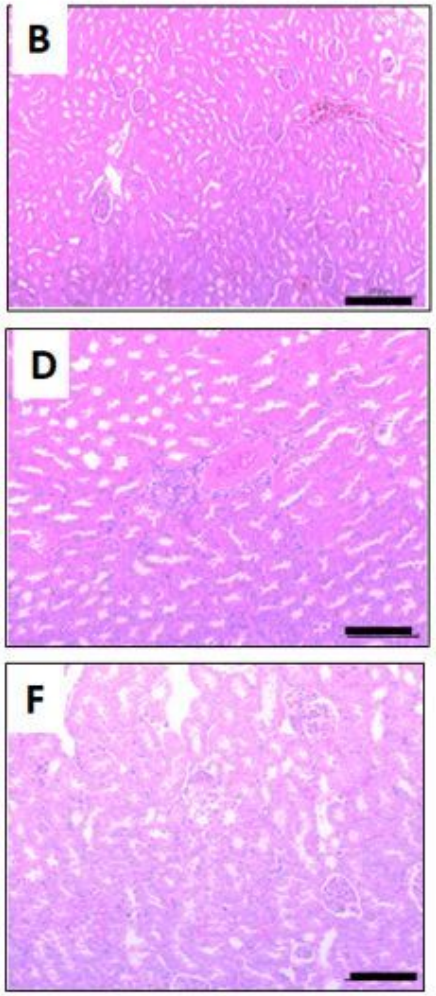
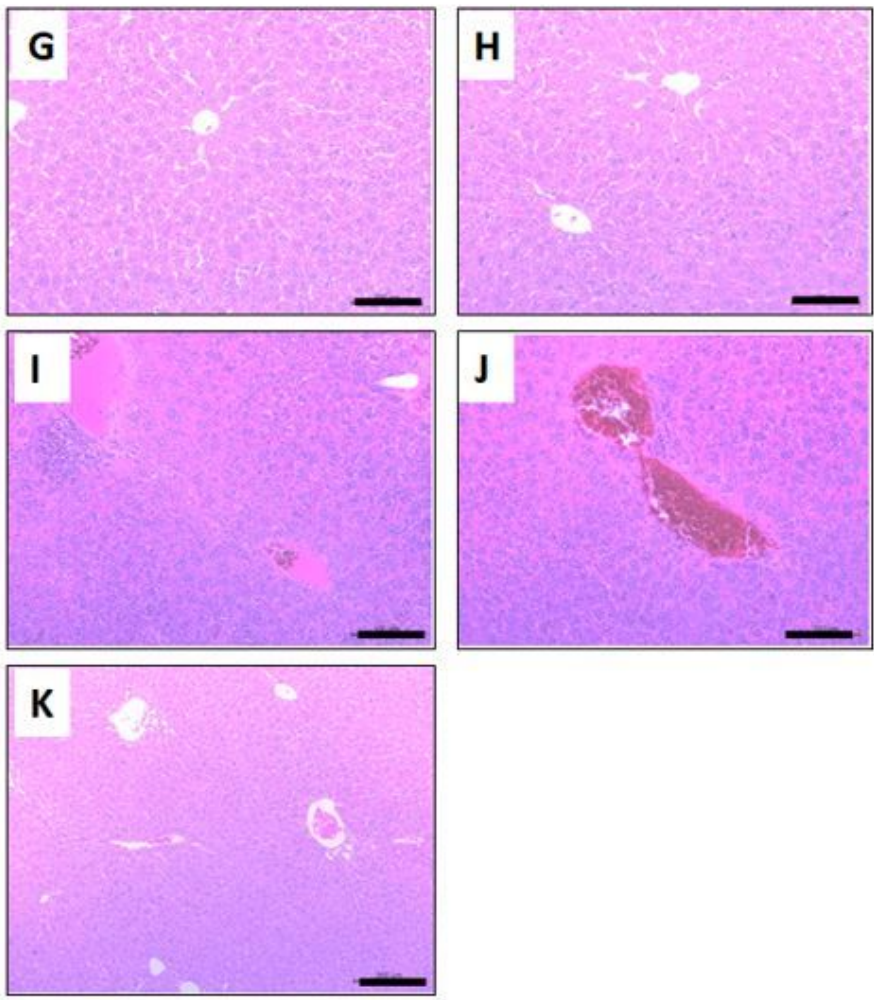

\section{Figure 6}

(A) normal control of mouse kidney. (B-D) Pronounced histopathological abnormalities are seen in mice treated with cisplatin (15 mg/kg body weight). (B) Congestion and partial atrophy of glomeruli in the cortex, (C) congestion and mild tubular degeneration in the cortico- medullary junction, (D) congestion and perarterial leucocytic aggregation in the medullary portion of the kidney. (E) Normal renal tubules in the cortico-medulry junction and normal collecting tubules (F) normal renal cortex be observed in the kidney of the MTN.5-AIQ-treated group. (G\&H) normal hepatic cords with normal hepatocytes in control group. (I\&J) Pronounced histopathological abnormalities are seen in mice treated with cisplatin (15 $\mathrm{mg} / \mathrm{kg}$ body weight. (I) Swelling and mild vascular degeneration in hepatocytes, $(\mathrm{J})$ congestion of both central and portal vein together with mononuclear aggregation. (K) Livers of MTN.5AIQ-treated mice 
shows nearly normal hepatic cords with normal hepatocytes and sinusoids. Scale bar=100 $\mu \mathrm{m}$. MTN.5AIQ; magnetic thermoresponsive nanocomposite loaded with 5-aminoisoquinoline.
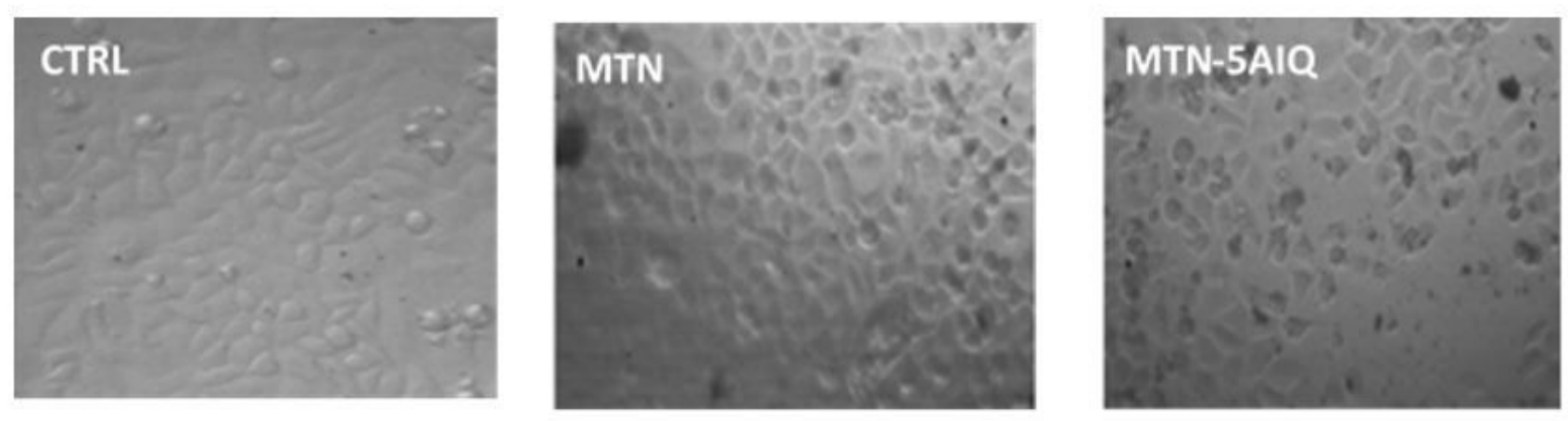

MTN

- MTN-5AIQ

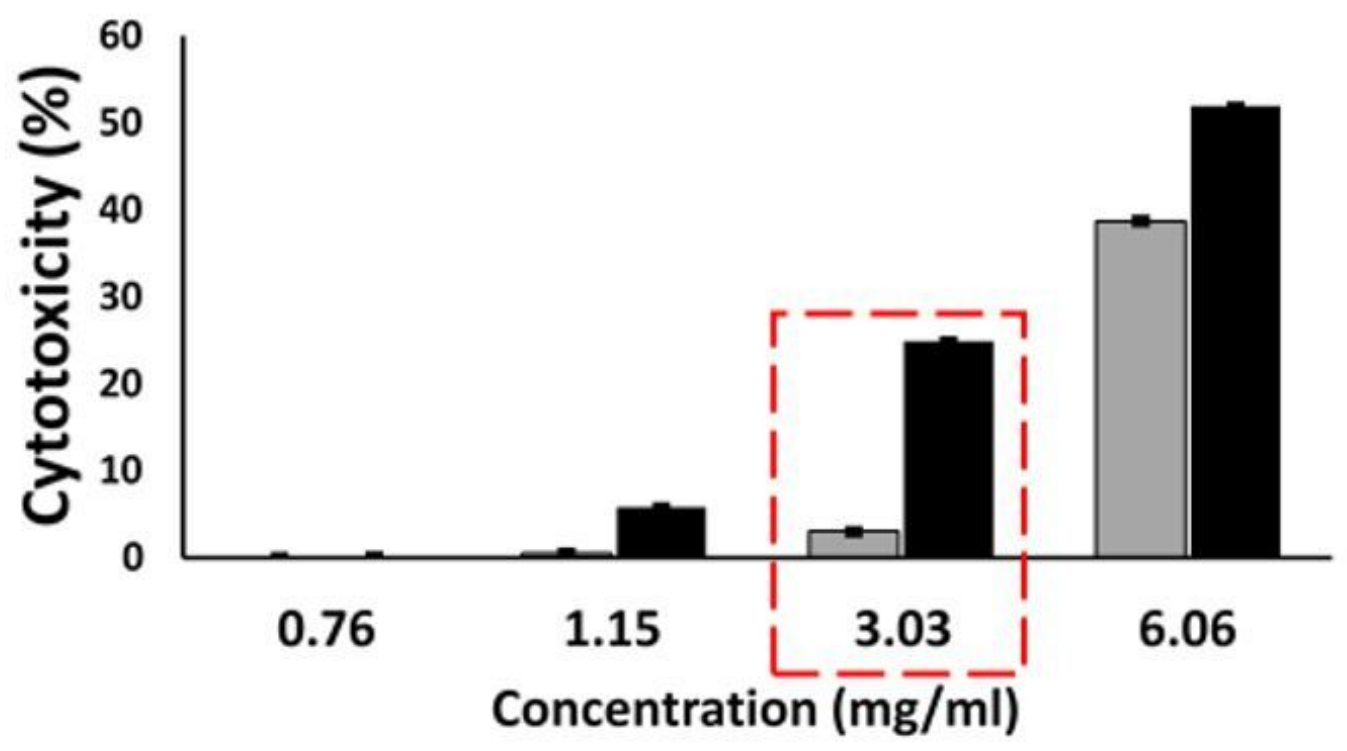

Figure 7

Cytotoxicity measurement of MTN and MTN.5-AIQ on Caco-2 cells; Caco-2 cells were incubated with different doses of either MTN unloaded or loaded composites. Twenty four hours later, cell viability was determined via MTT assay. MTN; magnetic thermoresponsive nanocomposite, MTN.5-AIQ; magnetic thermoresponsive nanocomposite loaded with 5-aminoisoquinoline.

\section{Supplementary Files}

This is a list of supplementary files associated with this preprint. Click to download. 
- Graphicalabstract.docx

- S.figurestables.docx 